\title{
APLICAÇÃO DE CONTROLE AVANÇADO EM PROCESSO DE LIXIVIAÇÃO*
}

\author{
Caio Oliveira Biondi ${ }^{1}$ \\ Danilo Lavigne Halla² \\ Paulo Roberto Edueta ${ }^{3}$ \\ Daniel Dayrell Pereira ${ }^{4}$ \\ Hector Ramalho Portugal ${ }^{5}$ \\ Maria José Dias ${ }^{6}$
}

\section{Resumo}

A lixiviação de zinco é um processo contínuo que ocorre através da adição de ácido em uma série de tanques, com objetivo de extrair o zinco do material de origem. $O$ ácido deve ser adicionado de forma progressiva para evitar a formação de compostos indesejados e também a formação de espuma decorrente da reação do ácido com o carbonato. O grande desafio do processo é acertar os pontos corretos de adição de ácido para que a lixiviação ocorra com o maior rendimento possível, pois tanto o excesso quanto a falta de ácido prejudicam essa etapa. Com o objetivo de aumentar o rendimento global do processo, a solução de controle avançado baseada em lógica Fuzzy da I.Systems, o Leaf, foi aplicado para substituir o controle tradicional PID e/ou manual. O Leaf foi capaz de reduzir a variabilidade do $\mathrm{pH}$ nos tanques em até $25 \%$, fazendo com que fosse possível operar mais tempo no ponto ótimo. Isso permitiu que o rendimento global da etapa de lixiviação aumentasse 0,24\%, além de melhoria qualitativa na etapa seguinte de sedimentação. $O$ ganho financeiro proporcionado pela economia de concentrado silicatado foi de 375.000 reais por ano para a Votorantim Metais.

Palavras-chave: Lixiviação; Controle Avançado de Processos; Zinco; Lógica Fuzzy.

\section{ADVANCED PROCESS CONTROL APPLICATION IN LEACHING}

\begin{abstract}
Zinc leaching is a continuous process that occurs through the addition of acid in a series of tanks with the goal of extracting zinc from the raw material. The acid must be added progressively to avoid the formation of undesired compounds and the formation of foam resulting from the reaction of the acid with the carbonate. The challenge of the process is adding acid at the correct points so that the leaching occurs with the highest possible efficiency, since both the excess and the lack of acid damage this step. In order to increase overall process performance, I.Systems' advanced fuzzy logic control solution, Leaf, was applied to replace traditional PID and/or manual control. Leaf was able to reduce the $\mathrm{pH}$ variability in the tanks by up to $25 \%$ making it possible to operate longer at the optimum point. This allowed the overall efficiency of the leaching step to increase by $0.24 \%$, in addition to a qualitative improvement in the next sedimentation step. The financial gain provided by the economy of silicate concentrate was 375,000 reais per year for Votorantim Metais.

Keywords: Leaching; Advanced Process Control; Zinc; Fuzzy Logic.

\footnotetext{
Engenheiro Químico, Mestre, Especialista em Controle, Aplicação, I.Systems, Campinas, SP, BR. Engenheiro de Computação, Diretor de Engenharia, Aplicação, I.Systems, Campinas, SP, BR. Engenheiro de Controle e Automação, Executivo de Contas, I.Systems, Campinas, SP, BR.
} Engenheiro Químico, Mestre, Gerente de Tecnologia, Votorantim Metais, Três Marias, SP, BR.
\end{abstract}


5 Engenheiro Metalúrgico, Engenheiro Sênior, Votorantim Metais, Três Marias, SP, BR.

6 Engenheira Química, Mestre, Engenheira Sênior, Votorantim Metais, Três Marias, SP, BR. 


\section{INTRODUÇÃO}

Lixiviação é o processo de extração de um ou mais constituintes solúveis de um sólido por meio de um solvente líquido. Trata-se de uma operação largamente utilizada no setor mínero-metalúrgico, a fim de se alcançar qualquer um dos seguintes propósitos principais: [1]

- abertura de minérios, concentrados ou produtos metalúrgicos, visando a solubilização de metais de interesse;

- solubilização de elementos de baixo valor (ganga) presentes em minérios, a fim de se concentrar e purificar os minerais de interesse no minério inicial (beneficiamento químico de minérios).

O fluxo de sólidos lixiviados, acompanhado de líquidos, é conhecido como "underflow" ou fluxo descendente; no campo da hidrometalurgia prática, é denominado lama. $\mathrm{O}$ fluxo de líquido contendo o soluto lixiviado é o "overflow"; como esse fluxo é normalmente o produto do processo de lixiviação, este recebe vários nomes opcionais: solução, licor ou lixiviado. [1]

A escolha do solvente, ou agente lixiviante, depende de fatores como:

- solubilidade - o constituinte sólido de interesse deve se dissolver rapidamente e em grande quantidade no agente lixiviante escolhido.

- seletividade - às vezes, escolhe-se um agente lixiviante mais seletivo, que possibilita a dissolução específica do constituinte de interesse, minimizando operações posteriores de purificação da solução resultante da lixiviação.

- viscosidade - soluções de baixa viscosidade melhoram a transferência de massa, diminuindo a camada limite entre a partícula e a solução. Essas soluções penetram mais rapidamente nos interstícios entre partículas sólidas e dentro dos poros de sólidos.

- custo, corrosividade, inflamabilidade e toxicidade - devem ser mínimos

De acordo com os critérios acima, a água é o agente lixiviante ideal, mas a sua ação é limitada a poucos minerais. Os agentes lixiviantes comumente utilizados incluem ácidos, bases e soluções salinas. [1]

\subsection{Principais Parâmetros nos Processos de Lixiviação}

Dentre os vários parâmetros importantes para os sistemas de lixiviação, destacam-se os mais frequentemente estudados: [1]

- Temperatura - de uma forma geral, temperaturas mais elevadas propiciam maiores percentuais de extração dos constituintes de interesse. Segundo a equação de Arrhenius (EQUAÇÃO (1)), observa-se que a velocidade das reações químicas aumenta com o aumento da temperatura, elevando, portanto, a velocidade de extração quando ocorre solubilização por reação química. Além disso, maiores temperaturas acarretam a diminuição da viscosidade para a maioria dos solventes comumente utilizados, facilitando a difusão deles em poros e interstícios. 


$$
k=k_{0} \times e^{\frac{-E}{R T}}
$$

- Concentração do agente lixiviante - a princípio, deve ser elevada o suficiente para garantir a solubilização da maior quantidade possível do mineral de interesse; no entanto, quando se empregam soluções de ácido sulfúrico $\left(\mathrm{H}_{2} \mathrm{SO}_{4}\right)$ como agente lixiviante, é preciso tomar cuidado com concentrações muito elevadas; o ácido sulfúrico envolve os seguintes equilíbrios de dissociação: $\mathrm{H}_{2} \mathrm{SO}_{4} \leftrightarrow \mathrm{H}^{+}+\mathrm{HSO}_{4}^{-} \mathrm{e}$ $\mathrm{H}_{2} \mathrm{SO}_{4}^{-} \leftrightarrow \mathrm{H}^{+}+\mathrm{SO}_{4}^{2-}$ pelo Princípio de Le Chatelier, percebe-se claramente que uma redução de $\mathrm{pH}$ (aumento da acidez) favorece a espécie completamente protonada (o H2SO4). Dependendo do minério, essa mudança de espécie presente pode mudar o mecanismo de reação, acelerando ou retardando, a lixiviação.

- Tamanho da partícula - a velocidade de extração é função direta do grau de liberação dos elementos de interesse; partículas menores implicam maior área superficial total disponível, favorecendo a solubilização desses; operações de cominuição, tais como a britagem e a moagem, representam custos elevados (alto gasto de energia), necessitando, portanto, de se investigar qual o tamanho de partícula capaz de garantir uma extração econômica e eficiente em um tempo de processo aceitável. Uma cominuição excessiva, além de resultar em desperdício de energia, reduz a eficiência de separadores sólido-liquido, como sedimentadores e filtros.

- Porosidade - sólidos porosos podem facilitar a chegada do agente lixiviante até o constituinte a ser solubilizado, dependendo da distribuição de tamanho desses poros e do tamanho desses em relação à partícula.

- Velocidade de agitação - quando a lixiviação ocorre em vasos sob agitação, mantendo os sólidos em uma suspensão, denominada polpa, o aumento da velocidade de agitação diminui a espessura da camada limite que envolve as partículas sólidas, diminuindo a resistência à difusão do soluto para o seio da solução e, consequentemente, favorecendo a extração.

\subsection{Lógica Fuzzy}

Ao se trabalhar com conceitos abstratos, não é possível perceber uma clara distinção entre estados e problemas de classificação que começam a surgir. A Lógica Fuzzy permite que estados indeterminados sejam quantificados. Dessa forma, conceitos abstratos como quente, muito frio, muito alto, etc., podem ser processados por um computador. [2]

Considerando percepções humanas sobre informações do nível de um tanque (baixo, alto, etc.), por exemplo: a transição entre os estados pode ser observada na Figura 1 como um gradiente, no qual não se pode afirmar exatamente onde um estado termina e outro começa. É possível inclusive categorizar um valor como pertencente em dois estados (com diferentes intensidades) ao mesmo tempo. [2] 


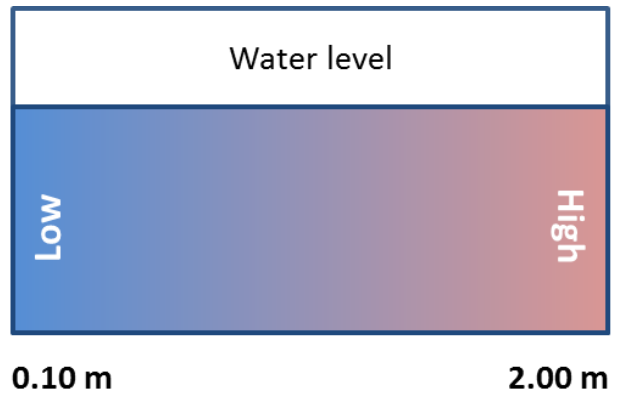

Figura 1. Gradiente de transição entre os estados de nível de um tanque.

De forma mais objetiva, alguém pode considerar que a $0.10 \mathrm{~m}$ de nível é $100 \%$ baixo e $0 \%$ alto. Ainda, que a $2.00 \mathrm{~m}$ de nível é $0 \%$ baixo e $100 \%$ alto. Dessa forma, por exemplo, o nível $0.48 \mathrm{~m}$ e $1.62 \mathrm{~m}$ são classificados como: [2]

- $0.48 \mathrm{~m}$ é $80 \%$ baixo e $20 \%$ alto.

- $1.62 \mathrm{~m}$ é $20 \%$ baixo e $80 \%$ alto.

Esse valor de classificação é conhecido como função de pertinência. Usando esse método é possível dizer que o nível $0.48 \mathrm{~m}$ é mais baixo que o nível $1.62 \mathrm{~m}$, assim como o nível $1.62 \mathrm{~m}$ é maior que o nível $0.48 \mathrm{~m}$. É importante ressaltar que em um processo real é necessário haver um grande número de funções de pertinência para ser realmente funcional.

Qualquer malha fechada começa pela medição dos erros dos sensores no processo em relação ao setpoint. O resultado dessa medida é utilizado para mudar o processo com o objetivo de diminuir a variabilidade. Utilizando lógica Fuzzy, é possível calcular qual seria o melhor valor para o atuador, seguindo as mesmas regras de controle utilizadas pelos operadores.

A primeira parte do desenvolvimento de um controle Fuzzy é a classificação das variáveis em funções de pertinência que representem a intensidade e direção em relação ao setpoint. Uma função de pertinência (também chamada de triângulo) é um estado (como alto e baixo, quente e frio) que define uma faixa de valores. A Figura 2 mostra os triângulos que representam o exemplo do nível do tanque.

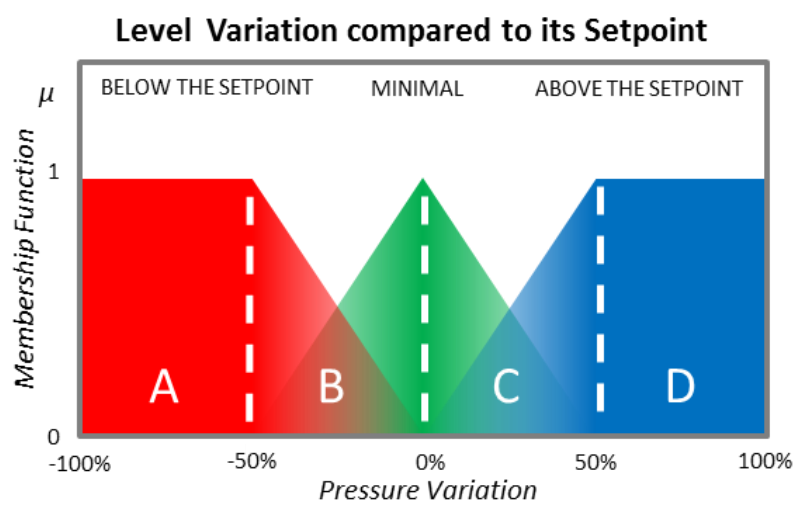

Figura 2. Classificação da variação do nível.

Nesse caso, variações perto do setpoint são consideradas na faixa de "mínimo". Na marca do setpoint (onde variações são iguais a $0 \%$ ) o valor é considerado 100\% 
mínimo. Seguindo a mesma definição, quanto maior a variação, menos sentido faz ele se enquadrar no triângulo de "mínimo", logo menos influência ele recebe.

Variações com intensidade maiores que 50\% param de ser consideradas mínimas ( $0 \%$ mínima). De maneira semelhante, variações abaixo de $0 \%$ são consideradas "abaixo do setpoint" e variações acima de $0 \%$ são chamadas de "acima do setpoint". Portanto, uma variação de $-25 \%$ é categorizada ao mesmo tempo como "mínima" e "abaixo do setpoint".

Considerando a presença de uma válvula sendo manipulada pelo operador para controlar o nível do tanque, o mesmo método de classificação pode ser aplicado à variável "abertura de válvula". Depois da categorização ser definida, o controlador Fuzzy usa um conjunto de regras para ajustar a abertura (saída) do sistema do nível do tanque (entrada). A Tabela 1 traz o conjunto de regras criadas para esse exemplo de nível de tanque.

Tabela 1. Regras utilizadas no controle do nível do tanque

\begin{tabular}{|c|c|c|}
\cline { 2 - 3 } \multicolumn{1}{c|}{ Regra } & $\begin{array}{c}\text { Nível Tanque } \\
\text { (entrada) }\end{array}$ & $\begin{array}{c}\text { Abertura } \\
\text { Válvula (saída) }\end{array}$ \\
\hline 1 & Abaixo & Máxima \\
2 & Mínima & Nominal \\
3 & Acima & Mínima \\
\hline
\end{tabular}

A variação no valor lido pelo sensor, em relação ao setpoint, pode ativar várias funções de pertinência em diferentes intensidades. Dessa forma, mais de uma regra pode ser ativada simultaneamente, fazendo com que várias funções de saída possam ser ativadas, com diferentes intensidades cada uma. $O$ controlador se torna mais preciso com o aumento do número de regras Fuzzy sendo utilizadas, o que permite descrever comportamentos cada vez mais complexos em diferentes cenários. (FRANCO, 2015)

\section{MATERIAIS E MÉTODOS}

A fim de reduzir a variabilidade dos $\mathrm{pHs}$ dos tanques e consequentemente aumentar o rendimento global do processo de lixiviação, a plataforma de controle avançado utilizada, baseada em lógica Fuzzy, foi aplicada em substituição ao controle tradicional PID e/ou manual existente. O software controla em tempo real a abertura da válvula e a vazão de solução de ataque.

Os passos de implementação da solução são descritos abaixo. Eles vão desde a análise da infraestrutura de automação até o momento em que o software começa a controlar todo o sistema.

1. Análise e adaptação da automação: criação de uma lógica de segurança watchdog e um botão de liga/desliga do software. Tudo foi instalado "acima" das lógicas préexistentes, então todos os intertravamentos de segurança foram mantidos. $O$ primeiro passo de instalação ainda inclui a aquisição e análise dos dados de processo (5 dias);

2. Avaliação do modelo e testes de escrita (5 dias); 
3. Criação de um modelo baseado em entrevistas com a equipe de operação e automação e análise das sugestões de controle em malha aberta (10 dias);

4. Controle em malha fechada. A partir desse passo o software está controlando a carga as válvulas de controle e os benefícios puderam começar a ser medidos (10 dias).

A elaboração da estratégia de controle é uma das etapas mais importantes na implementação do controle avançado. Com a estratégia correta, a plataforma será mais eficiente e capaz de antecipar os distúrbios e agir de forma ágil a fim de prevenir as oscilações e, portanto, estabilizar as variáveis de interesse, otimizando o processo.

Com isso em mente, o trabalho focou em determinar quais variáveis tinham o maior impacto em cada malha de controle. Nesse caso da lixiviação, as principais variáveis utilizadas foram os $\mathrm{pHs}$ dos quatro primeiros tanques, a temperatura dos tanques e a vazão de envio do tanque 1059 para os demais, a vazão da solução de ataque, receita dos filtros prensa e o número de bombas que enviam polpa da etapa anterior.

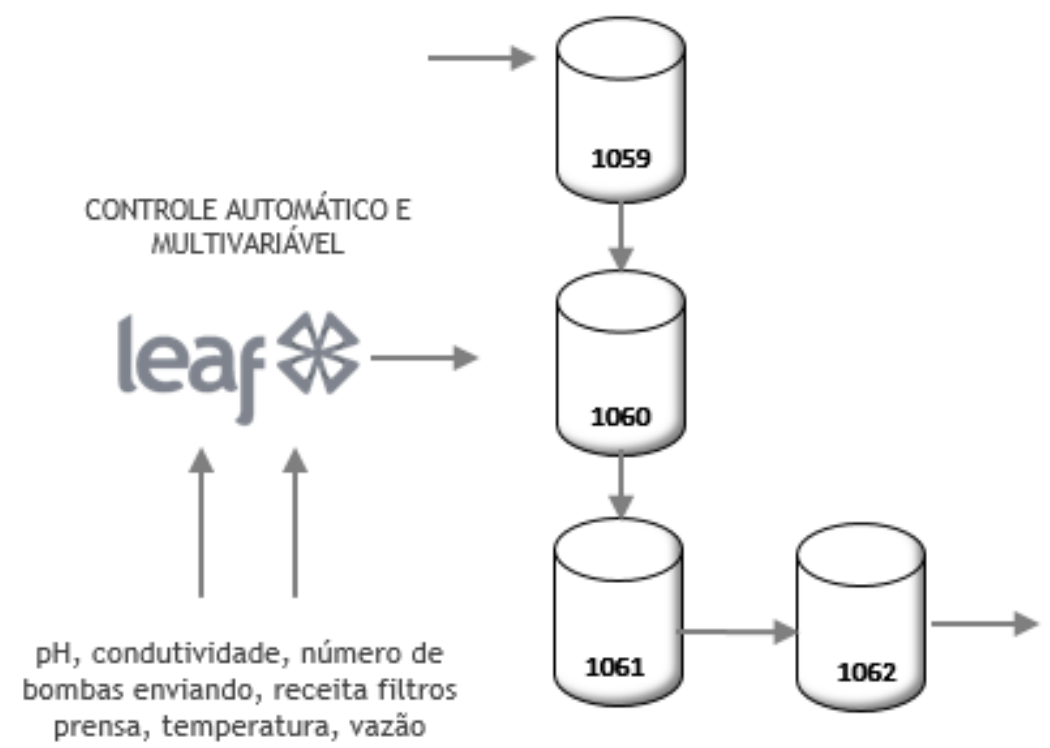

Figura 3. Esquema da estratégia de controle utilizada.

\section{RESULTADOS E DISCUSSÃO}

Para medir os ganhos provenientes do controle avançado, foram considerados três meses de período de avaliação após o fim da instalação. Durante esse período, o controle avançado foi alternado com o controle tradicional de acordo com um cronograma acordado para que fossem gerados dados com características parecidas de ritmo operacional e qualidade do minério. Nas figuras a seguir, é possível comparar a variabilidade dos pHs nos quatro primeiros tanques do processo de lixiviação, que foi reduzida em até $25 \%$. 


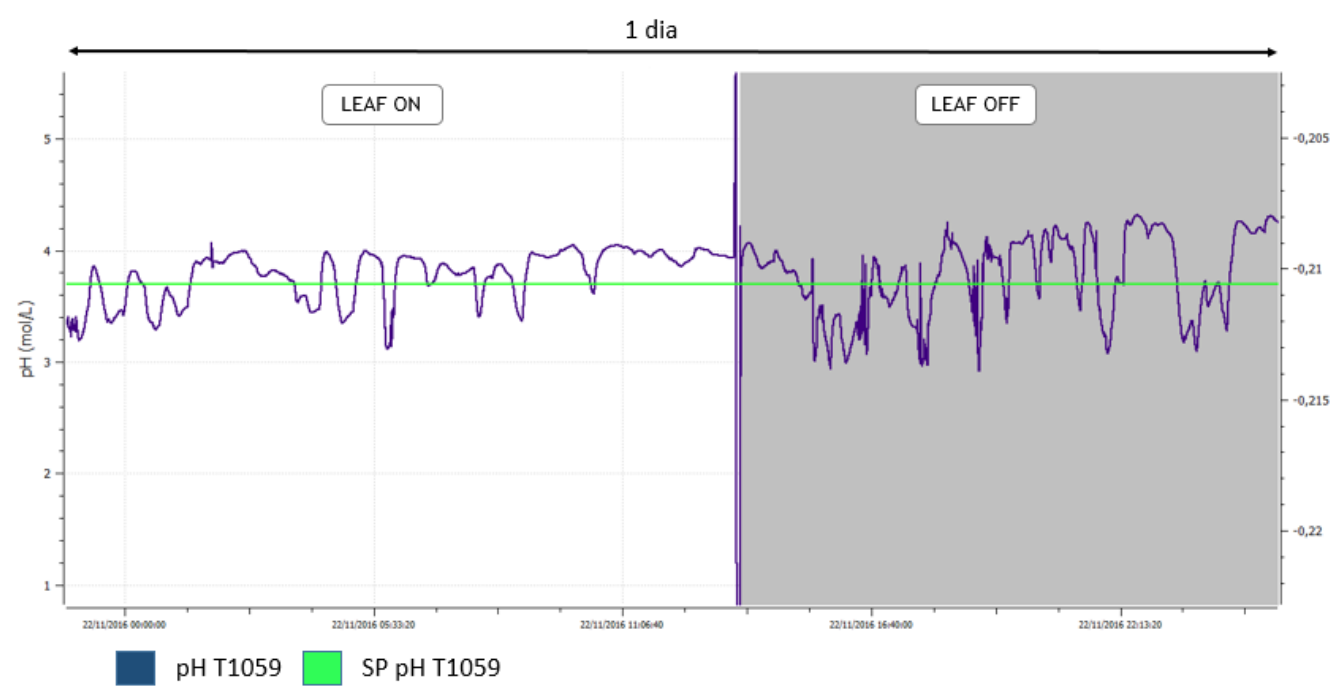

Figura 4. Variabilidade do $\mathrm{pH}$ do tanque 1059 com e sem controle avançado.

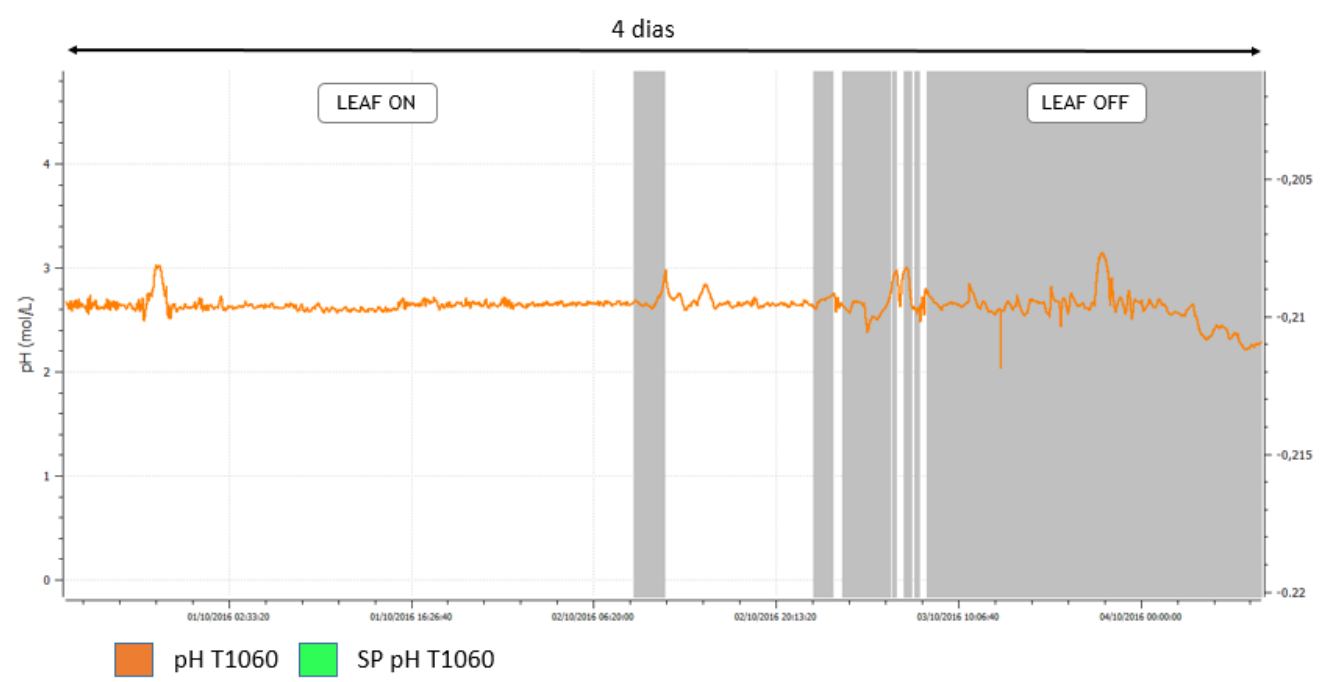

Figura 5. Variabilidade do $\mathrm{pH}$ do tanque 1060 com e sem controle avançado.

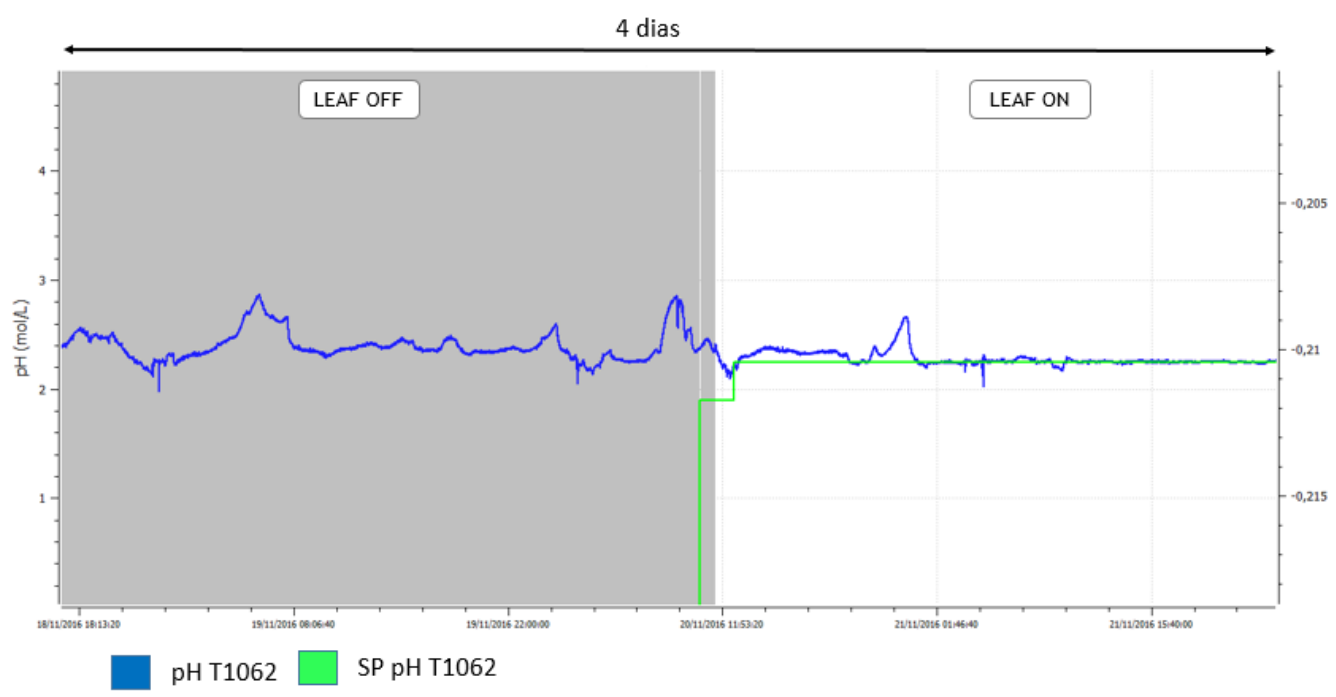

Figura 6. Variabilidade do $\mathrm{pH}$ do tanque 1062 com e sem controle avançado. 
A redução de variabilidade dos pHs observada nos dias em que a operação estava com controle avançado proporcionou uma operação mais estável e duradoura no ponto ótimo do processo. Um dos benefícios gerados foi a melhoria da etapa de sedimentação seguinte à lixiviação. Durante esses dias $60 \%$ das amostras analisadas apresentaram o clarificado límpido, contra apenas $20 \%$ com o controle tradicional.

Outro benefício gerado foi o aumento do rendimento global do processo de lixiviação, como pode ser observado na Figura 7 . Esse aumento de $0,24 \%$ representou cerca de 375.000 reais em economia de concentrado silicatado para a Votorantim Metais.

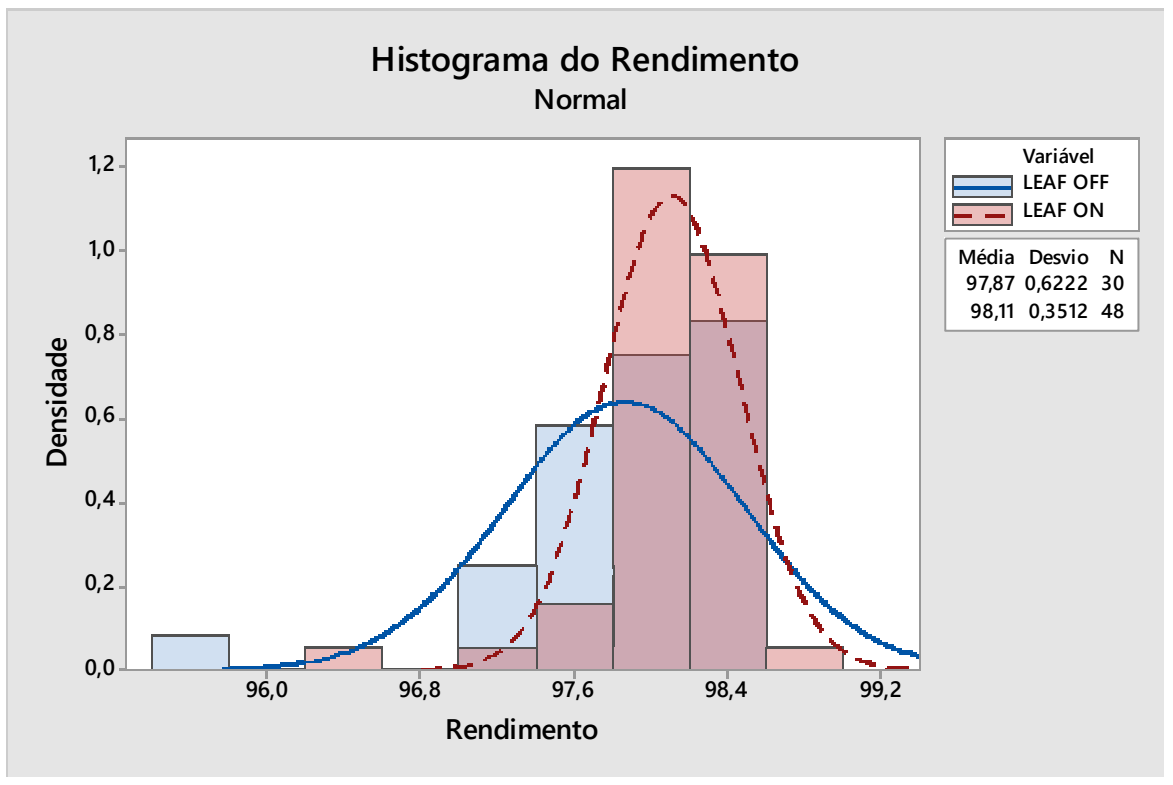

Figura 7. Aumento de rendimento global da lixiviação com controle avançado.

\section{CONCLUSÃO}

A plataforma de controle avançado utilizada se mostrou capaz de reduzir as oscilações de processo de lixiviação em até $25 \%$, que permitiu uma menor intervenção dos operadores no processo. Com isso, foi possível trabalhar no melhor ponto de operação do processo e aumentar a qualidade da etapa de sedimentação seguinte à lixiviação. Além disso, houve um aumento de $0,24 \%$ no rendimento global da lixiviação que representou um ganho anual de 375.000 de reais.

\section{Agradecimentos}

Agradecimento especial à equipe da Votorantim Metais e I.Systems que contribuíram nesse trabalho com dedicação, comprometimento e conhecimento.

\section{REFERÊNCIAS}

1 DIAS M.J. - Caracterização e avaliação da cinética de lixiviação do concentrado de zinco willemítico com presença de esfarelita - Dissertação de Mestrado, Universidade Federal de Minas Gerais, 2010.

2 FRANDO T., SENO R., DUCK A., CARNEIRO S., HALLA D., Santiago I., Advanced process control application in VM-CBA bauxite digestion unit, International Committee for Study of Bauxite, Alumina \& Aluminium, Dubai, 2015. 